\title{
DAMPAK DARI WORK LIFE BALANCE TERHADAP ORGANIZATIONAL COMMITMENT DOSEN SEKOLAH TINGGI ILMU EKONOMI INDRAGIRI RENGAT
}

\author{
Tomy Fitrio ${ }^{1}$, Puspa Dewi ${ }^{2}$ \\ Prodi Manajemen, Sekolah Tinggi Ilmu Ekonomi Indragiri (STIE-I) Rengat ${ }^{1,2}$ \\ Email: tomy@stieindragiri.ac.id, puspadewi@stieindragiri.ac.id
}

\begin{abstract}
Abstrak
Penelitian ini bertempat di Sekolah Tinggi Ilmu Ekonomi Indragiri Rengat, perumusan masalah adalah apakah Work life balance berdampak pada Organizational Commitment dosen Sekolah Tinggi Ilmu Ekonomi Indragiri Rengat. Tujuan penelitian adalah untuk menganalisis apakah Organizational Commitment di pengaruhi oleh Work Life Balance pada dosen Sekolah Tinggi Ilmu Ekonomi Indragiri Rengat. Sampel pada penelitian ini adalah 41 orang dosen Sekolah Tinggi Ilmu Ekonomi Indragiri Rengat, teknik pengambilan sampel adalah Saturated Sampling. Analisis menggunakan Descriptive analysis dan kuantitative analysis dengan memakai regresi linier. Hasil penelitian dapat disimpulkan organizational commitment di pengaruhi oleh work life balance secara positif dan signifikan pada dosen di Sekolah Tinggi Ilmu Ekonomi Indragiri Rengat.
\end{abstract}

Kata Kunci: Work Life Balance, Commitment Organizational

\section{PENDAHULUAN}

Komitmen organisasi dosen tidak hanya dalam bentuk berpartisipasi pada kegiatan pengajaran tetapi juga keterlibatan yang intens di bidang tridharma lainnya sehingga dapat menciptakan ketidakseimbangan antara tanggung jawab pribadi dan organisasi mereka. Untuk itu memastikan keseimbangan hidup dan pekerjaan sangat penting bagi dosen karena mereka harus meluangkan waktu untuk kegiatan penelitian, pengabdian masyarakat dan juga untuk keluarga mereka. Akademisi harus terlibat dalam kegiatan intelektual, lebih dari profesional lain karena akademisi akan menghasilkan luaran mahasiswa, penelitian yang akan berguna bagi masyarakat. Commitment organizational sangat penting saat ini dimana pengelolaan perguruan tinggi dan tuntutan perubahan membuat dosen lebih banyak menghabiskan waktu dikampus.

Mengelola kebutuhan organisasi dan pribadi dapat mempengaruhi tingkat produktivitas dan kepuasan karyawan yang mencerminkan tingkat komitmen karyawan terhadap organisasi (Veenhoven, 1988). Dosen bertanggung jawab untuk mempersiapkan lulusan yang kompeten untuk menciptakan generasi bangsa menjadi lebih baik. Sangat sulit bagi seorang dosen melaksanakan Work Life Balance. Oleh karena itu, sangat penting untuk menjelaskan makna antara variabel organizational commitment dan work life balance dosen dan dapat memecahkan masalah yang terkait dengan hal ini (Komal Saeed, 2014).

Sejumlah penelitian telah dilakukan memperlihatkan korelasi work life balance dan beberapa perilaku pekerjaan yang spesifik seperti organizational commitment dan job satisfaction (Doherty dan Manfredi 2006; Kinnie, Hutchinson, Purcell, Rayton dan Swart 2005; Scholarios \& Marks, 2004 ). Organizational commitmen dan work life balance keduanya penting karena, mempengaruhi efektivitas organisasi dan kesejahteraan keluarga. Ketegangan yang meningkat di tempat kerja secara negatif mempengaruhi kepuasan kerja, komitmen organisasi dan keseimbangan kehidupan kerja (Kossek, 2005; Bragger et. Al., 2005). Hubungan positif telah ditemukan antara work life balance, organizational commitment dan job satisfaction. Sedangkan work life balanced yang baik berhubungan negatif dengan niat untuk meninggalkan organisasi (Noor K. M., 2011). Karyawan merasa nyaman bekerja di organisasi yang membantu mereka menyeimbangkan antara kebutuhan 
kehidupan kerja dan kebutuhan kehidupan pribadi. Menurut penelitian Kinnie et al. (2007), upaya organisasi untuk menjaga keseimbangan pekerjaan dan kehidupan keluarga memiliki dampak positif pada tingkat komitmen karyawan di semua kelompok.

Sedangkan menurut Fisher dkk (2009), menyampaikan bahwa work-life balance memiliki 4 dimensi yaitu: (1) Gangguan kerja dengan kehidupan pribadi, (2) Gangguan kehidupan pribadi dengan pekerjaan, (3) Kemajuan pekerjaan pribadi, (4) kemajuan kerja dan kehidupan pribadi.

Penelitian (Fitrio, Apriansyah, Utami, \& Yaspita, 2019) menemukan bahwa kepuasan kerja berpengaruh terhadap komitmen organisasi. Dalam penelitian ini teori Allen dan meyer dipakai untuk melihat indikator organizational commitment (Allen dan Meyer, 1990): (1) Karakteristik pribadi individu, (2) Karakteristik organisasi, (3) Pengalaman organisasi.

\section{METODE PENELITIAN}

Penelitian ini berlokasi di Sekolah Tinggi Ilmu Ekonomi Indragiri (STIE-I) Rengat. jenis data adalah data kuantitatif. Sumber data adalah data primer. Populasi dalam penelitian ini adalah seluruh dosen Sekolah Tinggi Ilmu Ekonomi Indragiri (STIE-I) Rengat yang berjumlah 41 orang. Seluruh populasi akan dijadikan sampel (sampel jenuh).

Teknik analisis data yang dilakukan melalui beberapa tahapan sebagai berikut:

1. Uji Validitas dan Reabilitas

Uji Validitas, item dikatakan valid bila $r$ hitung $>r$ tabel, item reliabel jika ( $r$ h > rt).

2. Uji Asumsi Klasik

a. Uji Normalitas

Uji normalitas memakai uji Kolmogorov Smirnov yaitu: apabila nilai signifikan < 0,05 (taraf kepercayaan 95\%) distribusi adalah tidak normal. apabila nilai signifikan $>0,05$ (taraf kepercayaan 95\%) distribusi adalah normal

b. Uji Heterokedositas

Heteroskedastisitas dilihat dengan Grafik Plot Regresi dimana jika penyebaran tidak jelas, diatas dan dibawah angka 0 (Nol) pada sumbu Y, maka tidak terjadi heteroskedastisitas.

c. Uji Multikolinieritas

Sebelum menggunakan analisis regresi linear terlebih dahulu dilakukan Uji Multikolinearitas. Uji ini dapat dilihat dari nilai VIF (Varians Inflation Factor). Jika angka tolerance $<1$ atau nilai $V I F>10$, maka ada indikasi terjadi multikolinearitas

3. Analisis Deskriptif

Analisis deskriptif dilakukan untuk memaknai sifat dan karakter data. seperti nilai Mean, Median, Sum dan lainnya.

4. Regresi Linier Sederhana

Analisia Regresi Linear sederhana dipakai untuk menganalisis impact antara variabel dependent terhadap variabel independent

Persamaan Regresi:

Keterangan :

$$
\mathbf{Y}=\mathbf{a}+\mathbf{b}_{1} \mathbf{X}_{1}+\mathbf{e}
$$

$\mathrm{Y}=$ organizational commitment

$\mathrm{a}=$ konstanta

$\mathrm{b}_{1}=$ koefisien regresi

$\mathrm{X}=$ work life balance

Dengan persamaan : 


$$
\begin{aligned}
& \sum \mathrm{Y}=a n+b_{1} \sum X_{1} \\
& \sum X_{1} Y=a \sum X_{1}+b_{1} \sum X^{2}{ }_{1}
\end{aligned}
$$

5. Koefisien Korelasi

Untuk melihat pengaruh seluruh variabel independen terhadap variabel dependen diberi notasi " $R$ "

$\mathrm{R}=\sqrt{\frac{\left(b_{1} \sum y x_{1}\right)+\left(b_{2} \sum y x_{2)}\right.}{\left(\sum y^{2}\right)}}$

Dimana :

- Apabila $\mathrm{R} \leq+1$ artinya memiliki hubungan yang erat namun searah

- Apabila $\mathrm{R} \geq-1$ artinya memiliki hubungan yang erat namun berlawanan arah

6. Koefisien Determinasi

Tujuan metode ini untuk menganalisis seberapa besar persentase korelasi variabel-variabel yang diteliti dengan rumus :

$$
\mathbf{R}^{2}=\frac{\left(b_{1} \sum y x_{1}\right)}{\left(\sum y^{2}\right)}
$$

7. Uji Hipotesis

Dimana:

$\mathrm{Ho}=\mathrm{b}=0$ work life balance tidak berpengaruh signifikan terhadap organizational commitment

$\mathrm{Ha}=\mathrm{b} \neq$ work life balance berpengaruh signifikan terhadap organizational commitment Los $(\alpha)$ (level of significance) / batas Toleransi antara1\% - 10\%.

$\mathrm{t}$ Tabel $=\alpha / 2 ; \mathrm{n}-2$

t hitung $=\frac{b-b o}{s b}$

Artinya :

Apabila $\mathrm{t}$ hitung $>\mathrm{t}$ tabel, Ha diterima dan Ho ditolak atau tidak sama dengan 0 artinya ada pengaruh yang signifikan antara variabel independen dan Variabel dependen

Apabila $\mathrm{t}$ hitung $<\mathrm{t}$ tabel, Ha ditolak dan Ho diterima atau sama dengan 0 artinya tidak ada pengaruh yang signifikan antara independent variabel dan dependent variabel.

\section{HASIL DAN PEMBAHASAN}

1. Uji Validitas dan reabilitas

Tabel 1: Hasil Uji Validitas dan Reabilitas

\section{Reliability Statistics}

$0.757 \quad 18$




\section{Item-Total Statistics}

\begin{tabular}{|c|c|c|c|c|}
\hline & $\begin{array}{c}\text { Scale Mean if Item } \\
\text { Deleted }\end{array}$ & $\begin{array}{c}\text { Scale Variance if Item } \\
\text { Deleted }\end{array}$ & $\begin{array}{l}\text { Corrected } \\
\text { Item-Total } \\
\text { Correlation }\end{array}$ & $\begin{array}{c}\text { Cronbach's } \\
\text { Alpha if Item } \\
\text { Deleted }\end{array}$ \\
\hline item1 & 97.51 & 313.441 & 0.557 & 0.748 \\
\hline item2 & 97.48 & 314.250 & 0.514 & 0.748 \\
\hline item3 & 97.74 & 303.962 & 0.598 & 0.740 \\
\hline item4 & 97.57 & 313.952 & 0.542 & 0.748 \\
\hline item5 & 98.33 & 313.420 & 0.545 & 0.748 \\
\hline item6 & 99.05 & 313.843 & 0.578 & 0.748 \\
\hline item7 & 98.75 & 309.719 & 0.514 & 0.745 \\
\hline item8 & 98.81 & 301.954 & 0.838 & 0.737 \\
\hline item9 & 98.83 & 302.255 & 0.828 & 0.737 \\
\hline item10 & 98.83 & 302.262 & 0.827 & 0.737 \\
\hline item11 & 98.52 & 309.854 & 0.650 & 0.744 \\
\hline item12 & 98.81 & 301.954 & 0.838 & 0.737 \\
\hline item13 & 97.62 & 310.952 & 0.635 & 0.745 \\
\hline item14 & 98.81 & 301.954 & 0.838 & 0.737 \\
\hline item15 & 97.57 & 313.952 & 0.542 & 0.748 \\
\hline item16 & 97.57 & 313.952 & 0.542 & 0.748 \\
\hline item17 & 98.23 & 316.316 & 0.384 & 0.751 \\
\hline item18 & 98.51 & 311.284 & 0.445 & 0.747 \\
\hline Total & 50.53 & 81.906 & 1.000 & 0.917 \\
\hline
\end{tabular}

Pada Tabel 1 di atas, nilai Scale Corrected Item-Total Correlation adalah nilai Validitas Butir sedangkan nilai Croncbach's Alpha if Item Deleted adalah nilai Reliabilitas Butir. Bandingkan $\mathrm{R}$ Tabel dan R hitung. R hitung adalah 0,3783. Pada tabel 1 pada kolom Corrected Item-Total Correlation dapat kita lihat semua nilainya besar dari 0,3783 dapat disimpulan semua butir pertanyaan adalah valid. Nilai Cronbach's Alpha Based on Standardized Items, nilai tersebut $0,757>\mathrm{R}$ tabel 0,3783 . Berarti item pertanyaan reliabel semuanya. 
Volume VIII, No. 01, September 2019

\section{Uji Asumsi Klasik}

a. Uji Normalitas

Gambar 1: Uji Normalitas

Normal P-P Plot of Regression Standardized Residual

Dependent Variable: ORGANIZATIONAL COMMITMENT

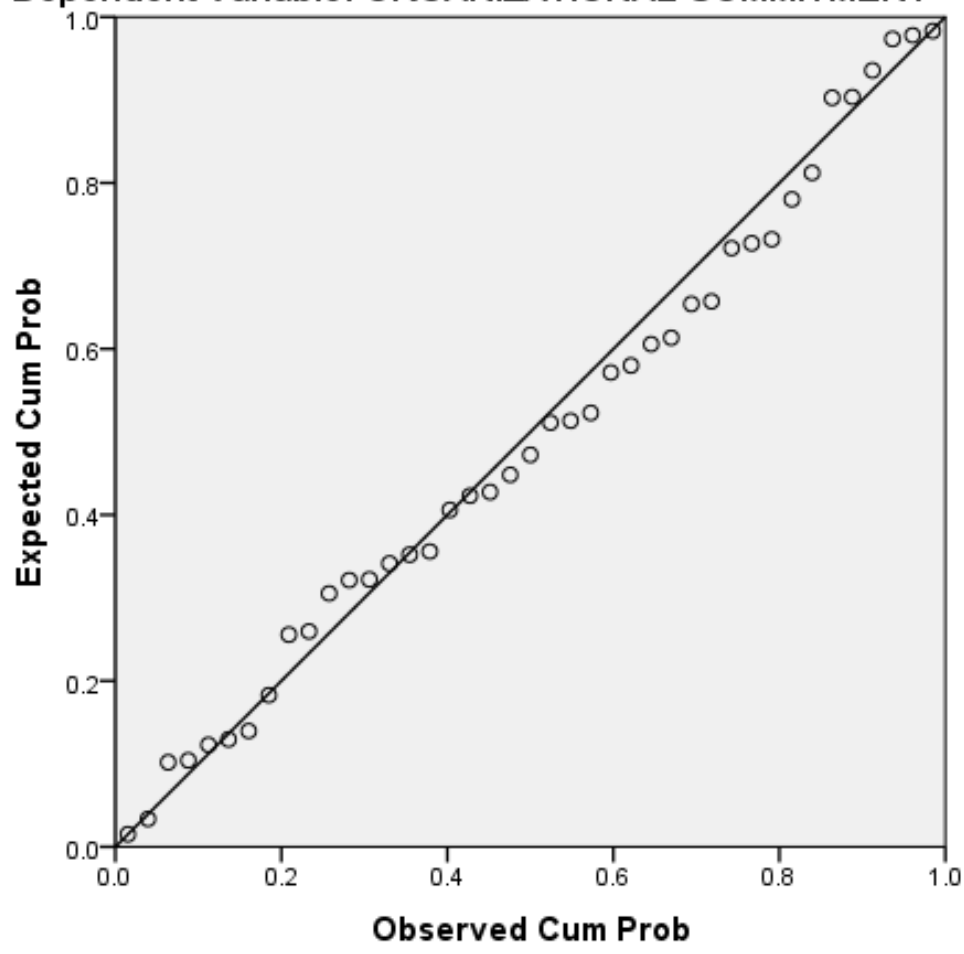

Dari gambar 1 dapat kita lihat kalau penyebaran berada disekitar sumbu, artinya data berdistribusi normal.

\section{b. Uji Heterokedasitas}

Tabel 2: Uji Heterokedasitas

\section{Uji Heteroskedastisitas}

\begin{tabular}{|c|c|c|c|c|c|c|c|}
\hline \multirow[b]{3}{*}{ Model } & \multicolumn{4}{|c|}{ Coefficients $^{a}$} & & & \\
\hline & \multicolumn{2}{|c|}{$\begin{array}{l}\text { Unstandardized } \\
\text { Coefficients }\end{array}$} & \multirow{2}{*}{$\begin{array}{c}\text { Standardized } \\
\text { Coefficients } \\
\text { Beta }\end{array}$} & \multirow{3}{*}{$\frac{t}{7.471}$} & \multirow{3}{*}{$\begin{array}{l}\text { Sig. } \\
0.000\end{array}$} & \multicolumn{2}{|c|}{ Collinearity Statistics } \\
\hline & B & Error & & & & Tolerance & VIF \\
\hline $1 \quad$ (Constant) & 15.213 & 2.036 & & & & & \\
\hline $\begin{array}{l}\text { WORK LIFE } \\
\text { BALANCE }\end{array}$ & 0.212 & 0.042 & 0.628 & 5.045 & 0.000 & 1.000 & 1.000 \\
\hline
\end{tabular}

a. Dependent Variable: ORGANIZATIONAL COMMITMENT

Dari hasil pengujian pada Tabel 2 dapat dilihat bahwa nilai signifikansi semua variabel $>0.05$. Hal ini dapat disimpulkan bahwa tidak terjadi hetersokedastisitas pada model.

\section{c. Uji Multikolineritas}

Jika nilai tolerance $<0,10$ dan nilai VIF suatu variabel bebas $>10$, maka dapat disimpulkan bahwa variabel bebas tersebut terjadi Multikolinearitas. dari tabel 2 
telihat tolerance $<0,10$ dan VIF tidak $>10$ dapat disimpulkan tidak terjadi multikolinieritas.

\section{Analisa Deskriptif}

Gambar 2: Masa Kerja Sebagai Dosen
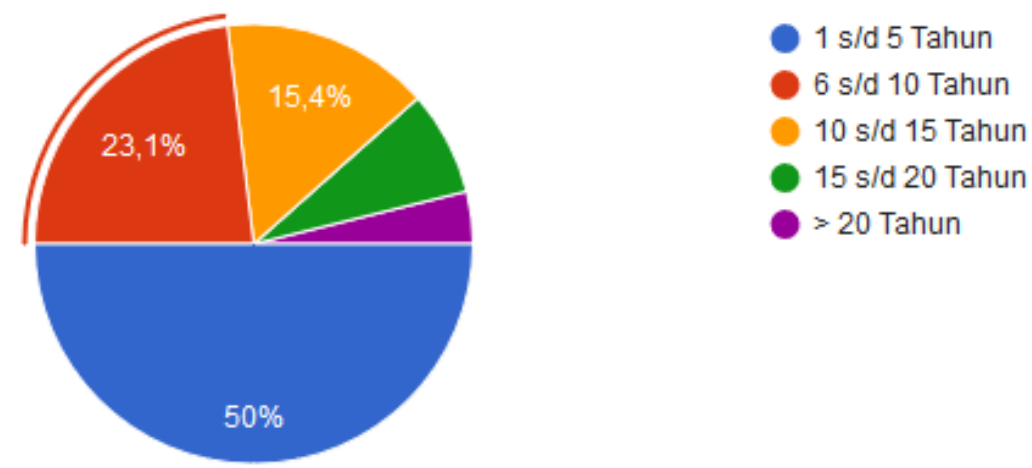

Dari gambar 2 tentang masa kerja sebagai dosen dapat kita baca bahwa lima puluh persen responden mempunyai masa kerja satu sampai dengan lima tahun, dua puluh tiga persen dengan masa kerja lima sampai sepuluh tahun dan sisanya adalah masa kerja diatas sepuluh tahun. Dapat kita lihat bahwasanya dosen STIE Indragiri masih baru, diharapkan mempunyai komitmen yang tinggi untuk mengembangkan organisasi,

Gambar 3: Jabatan Fungsional

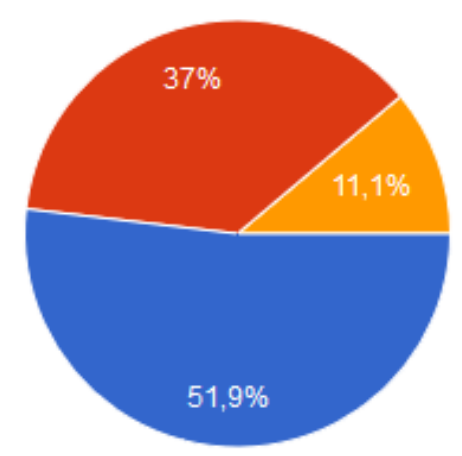

Belum Punya Jabatan Fungsional

Asisten Ahli

Lektor

Lektor Kepala

Dari gambar 3 tentang jabatan fungsional dapat kita baca bahwasanya lima puluh satu persen responden belum mempunyai jabatan fungsional, tiga puluh tujuh persen asisten ahli dan sisanya sebelas persen adalah lektor. Untuk dosen yang lektor kepala belum ada di STIE Indragiri Rengat. 
Volume VIII, No. 01, September 2019

Tabel 3: Distribusi Frekuensi Variabel Work Life Balance Dosen STIE Indragiri

\begin{tabular}{|c|c|c|c|c|c|c|c|c|c|c|c|c|c|c|c|c|}
\hline & \multirow{3}{*}{ Butir Pertanyaan } & \multicolumn{10}{|c|}{ Nilai } & \multirow{2}{*}{\multicolumn{2}{|c|}{ Total }} & \multirow{3}{*}{$\begin{array}{l}\text { Skor } \\
\text { rata- } \\
\text { rata }\end{array}$} & \multirow{3}{*}{ Penc } & \multirow{3}{*}{ Ket } \\
\hline & & \multicolumn{2}{|c|}{ (5) } & \multicolumn{2}{|c|}{ (4) } & \multicolumn{2}{|c|}{ (3) } & \multicolumn{2}{|c|}{ (2) } & \multicolumn{2}{|c|}{ (1) } & & & & & \\
\hline & & $\mathrm{f}$ & $\%$ & $f$ & $\%$ & $\mathrm{f}$ & $\%$ & $\mathrm{f}$ & $\%$ & $\mathrm{f}$ & $\%$ & $\mathrm{f}$ & $\%$ & & & \\
\hline 1 & $\begin{array}{l}\text { Waktu bekerja membatasi } \\
\text { kehidupan pribadi }\end{array}$ & 15 & 36,6 & 19 & 46,3 & 6 & 14,6 & 1 & 2,4 & 0 & 0 & 41 & 100 & 4,17 & 83,4 & Baik \\
\hline 2 & $\begin{array}{l}\text { Pekerjaan membuat sulit } \\
\text { menjalani kehidupan } \\
\text { pribadi }\end{array}$ & 5 & 39,0 & 18 & 43,9 & 6 & 14,6 & 1 & 2,4 & 0 & 0 & 41 & 100 & 4,20 & 84 & Baik \\
\hline 3 & $\begin{array}{l}\text { Banyak kehilangan } \\
\text { waktu kehidupan pribadi } \\
\text { karena pekejaan }\end{array}$ & 17 & 41,5 & 12 & 29,3 & 2 & 4,9 & 8 & 19,5 & 1 & 4,9 & 41 & 100 & 3,83 & 76,6 & Baik \\
\hline 4 & $\begin{array}{l}\text { Banyak waktu kerja } \\
\text { tersita untuk urusan } \\
\text { pribadi }\end{array}$ & 13 & 31,7 & 20 & 48,8 & 7 & 17,1 & 1 & 2,4 & 0 & 0 & 41 & 100 & 4,10 & 82 & Baik \\
\hline 5 & $\begin{array}{l}\text { Aktivitas kehidupan } \\
\text { pribadi membuat sulit } \\
\text { melakukan pekerjaan } \\
\text { dengan baik. }\end{array}$ & 2 & 4,9 & 11 & 26,8 & 21 & 51,2 & 5 & 12,2 & 1 & 4,9 & 41 & 100 & 3,15 & 63 & $\begin{array}{l}\text { Cukup } \\
\text { Baik }\end{array}$ \\
\hline 6 & $\begin{array}{l}\text { Kepentingan pribadi } \\
\text { tidak menyebabkan } \\
\text { pekerjaan tertunda }\end{array}$ & 0 & 0 & 3 & 7,3 & 8 & 19,5 & 23 & 56,1 & 7 & 17,1 & 41 & 100 & 2,17 & 43,4 & $\begin{array}{c}\text { Kurang } \\
\text { Baik }\end{array}$ \\
\hline 7 & $\begin{array}{l}\text { Aktivitas kehidupan } \\
\text { pribadi mendukung } \\
\text { dalam menjalankan } \\
\text { pekerjaan }\end{array}$ & 3 & 7,3 & 7 & 17,1 & 6 & 14,6 & 19 & 46,3 & 6 & 14,6 & 41 & 100 & 2,56 & 51,2 & $\begin{array}{c}\text { Kurang } \\
\text { Baik }\end{array}$ \\
\hline 8 & \begin{tabular}{|l} 
Suasana pekerjaan \\
mendukung aktivitas \\
kehidupan pribadi
\end{tabular} & 1 & 2,4 & 7 & 17,1 & 12 & 29,3 & 13 & 31,7 & 8 & 19,5 & 41 & 100 & 2,51 & 50,2 & $\begin{array}{c}\text { Kurang } \\
\text { Baik }\end{array}$ \\
\hline 9 & $\begin{array}{l}\text { Senang dengan } \\
\text { kehidupan pribadi \& } \\
\text { pekerjaan sekarang }\end{array}$ & 1 & 2,4 & 7 & 17,1 & 11 & 26,8 & 14 & 53,7 & 8 & 19,5 & 41 & 100 & 2,49 & 49,8 & $\begin{array}{c}\text { Kurang } \\
\text { Baik }\end{array}$ \\
\hline & Rata-rata & 6,3 & 18,4 & 11,5 & 28,1 & 8,7 & 21,4 & 9,4 & 25,1 & 3,4 & 8,9 & 41 & 100 & 3,24 & 64,8 & $\begin{array}{l}\text { Cukup } \\
\text { Baik }\end{array}$ \\
\hline
\end{tabular}

Sumber: Data primer (diolah)

Untuk keseluruhan variabel Work Life Balance ini skor rata-rata adalah 3,24 tingkat capaian 64,8 persen dengan kriteria cukup baik, artinya dosen STIE Indragiri Rengat kurang mempunyai keseimbangan antara pekerjaan dan kehidupan pribadi. 
Tabel 4: Distribusi Frekuensi Variabel Organizational Commitment Dosen STIE Indragiri

\begin{tabular}{|c|c|c|c|c|c|c|c|c|c|c|c|c|c|c|c|c|}
\hline \multirow{3}{*}{ No } & \multirow{3}{*}{ Butir Pertanyaan } & \multicolumn{10}{|c|}{ Nilai } & \multirow{2}{*}{\multicolumn{2}{|c|}{ Total }} & \multirow{3}{*}{$\begin{array}{l}\text { Skor } \\
\text { rata- } \\
\text { rata }\end{array}$} & \multirow{3}{*}{ Penc } & \multirow{3}{*}{ Ket } \\
\hline & & \multicolumn{2}{|c|}{ (5) } & \multicolumn{2}{|c|}{ (4) } & \multicolumn{2}{|c|}{ (3) } & \multicolumn{2}{|c|}{ (2) } & \multicolumn{2}{|c|}{ (1) } & & & & & \\
\hline & & $\mathrm{f}$ & $\%$ & $\mathrm{f}$ & $\%$ & f & $\%$ & $\mathrm{f}$ & $\%$ & $\mathrm{f}$ & $\%$ & $\mathrm{f}$ & $\%$ & & & \\
\hline 1 & $\begin{array}{l}\text { Senang bekerja di STIE } \\
\text { Indragiri hingga pensiun }\end{array}$ & 1 & 2,4 & 4 & 17,1 & 11 & 26,8 & 14 & 34,1 & 8 & 19,5 & 41 & 100 & 2,49 & 49,8 & $\begin{array}{c}\text { Kurang } \\
\text { Baik }\end{array}$ \\
\hline 2 & $\begin{array}{l}\text { Senang membicarakan } \\
\text { hal positif tentang STIE } \\
\text { Indragiri }\end{array}$ & 2 & 4,9 & 8 & 19,5 & 16 & 39,0 & 13 & 31,7 & 1 & 4,9 & 41 & 100 & 2,88 & 57,6 & $\begin{array}{c}\text { Cukup } \\
\text { Baik }\end{array}$ \\
\hline 3 & $\begin{array}{l}\text { Masalah STIE Indragiri } \\
\text { adalah masalah saya } \\
\text { juga }\end{array}$ & 1 & 2,4 & 7 & 17,1 & 12 & 29,3 & 13 & 31,7 & 8 & 19,5 & 41 & 100 & 2,51 & 50,2 & $\begin{array}{c}\text { Kurang } \\
\text { Baik }\end{array}$ \\
\hline 4 & $\begin{array}{l}\text { Tetap bekerja di STIE } \\
\text { Indragiri }\end{array}$ & 13 & 31,7 & 17 & 41,5 & 10 & 24,4 & 1 & 2,4 & 0 & 0 & 41 & 100 & 4,02 & 80,4 & Baik \\
\hline 5 & $\begin{array}{l}\text { Merasa lebih banyak } \\
\text { kerugian jika keluar dari } \\
\text { pekerjaan }\end{array}$ & 1 & 2,4 & 7 & 17,1 & 12 & 29,3 & 13 & 31,7 & 8 & 19,5 & 41 & 100 & 2,51 & 50,2 & $\begin{array}{c}\text { Kurang } \\
\text { baik }\end{array}$ \\
\hline 6 & $\begin{array}{l}\text { Tetap bekerja pada STIE } \\
\text { Indragiri karena PTS } \\
\text { lain belum tentu } \\
\text { memberi benefit yang } \\
\text { lebih baik }\end{array}$ & 13 & 31,7 & 20 & 48,8 & 7 & 17,1 & 1 & 2,4 & 0 & 0 & 41 & 100 & 4,10 & 82 & Baik \\
\hline 7 & $\begin{array}{l}\text { Loyalitas pada STIE } \\
\text { Indragiri adalah faktor } \\
\text { penting }\end{array}$ & 13 & 31,7 & 20 & 48,8 & 7 & 17,1 & 1 & 2,4 & 0 & 0 & 41 & 100 & 4,10 & 82 & Baik \\
\hline 8 & $\begin{array}{l}\text { Berpindah pekerjaan } \\
\text { karena tawaran yang } \\
\text { lebih baik merupakan } \\
\text { hal yang tidak benar }\end{array}$ & 4 & 9,8 & 14 & 34,1 & 14 & 34,1 & 7 & 17,1 & 2 & 4,9 & 41 & 100 & 3,27 & 65,4 & $\begin{array}{l}\text { Cukup } \\
\text { baik }\end{array}$ \\
\hline 9 & $\begin{array}{l}\text { Merasa bersalah jika } \\
\text { pindah ke PTS lain. }\end{array}$ & 5 & 12,2 & 6 & 14,6 & 14 & 34,1 & 11 & 26,8 & 5 & 12,2 & 41 & 100 & 2,88 & 57,6 & $\begin{array}{l}\text { Cukup } \\
\text { baik }\end{array}$ \\
\hline & Rata-rata & 5,8 & 14,3 & 11,4 & 28,7 & 11,4 & 27,9 & 8,2 & 20,0 & 3,5 & 8,9 & 41 & 100 & 3,1 & 62 & $\begin{array}{l}\text { Cukup } \\
\text { baik }\end{array}$ \\
\hline
\end{tabular}

Sumber: Data primer (diolah)

Untuk keseluruhan variabel Organizational Commitment skor rata-rata adalah 3,1 tingkat capaian 62 persen dengan kriteria cukup baik, artinya komitmen dosen STIE Indragiri Rengat terhadap organisasi kurang.

4. Analisa Regresi Linier Sederhana

Tabel 5: Hasil Uji Regresi Linier Sederhana

\section{Coefficients $^{\mathrm{a}}$}

\begin{tabular}{|c|c|c|c|c|c|c|}
\hline \multirow[b]{2}{*}{ Model } & & \multicolumn{2}{|c|}{ Unstandardized Coefficients } & \multirow{2}{*}{$\begin{array}{c}\text { Standardized } \\
\text { Coefficients } \\
\text { Beta }\end{array}$} & \multirow[b]{2}{*}{$\mathrm{t}$} & \multirow[b]{2}{*}{ Sig. } \\
\hline & & $\mathrm{B}$ & Std. Error & & & \\
\hline 1 & (Constant) & 15.213 & 2.036 & & 7.471 & .000 \\
\hline & WORK LIFE BALANCE & .212 & .042 & .628 & 5.045 & .000 \\
\hline
\end{tabular}


Dengan variabel dependen adalah Organizational Commitment dosen STIE Indragiri dan variabel independen adalah Working Life Balance. Adapun hasil uji regresi linier berganda pada penelitian ini dapat dilihat pada tabel 5 dengan rumus sbb: $\mathrm{OC}=15,213+0,212 \mathrm{X}+\mathrm{e}$

Artinya jika $\mathrm{a}=15.213$ dan organizational commitment sama dengan 0 (nol) maka besarnya komitment organisasi adalah 15,213 dan jika organizational commitment meningkat sebesar 1 (satu) satuan, maka kinerja akan mengalami peningkatan sebesar 0,212 poin.

5. Koefisien Korelasi dan Determinasi

Tabel 6: Koefisien Korelasi dan Determinasi

\section{Model Summary}

\begin{tabular}{|c|c|c|c|c|c|}
\hline Model & $\mathrm{R}$ & R Square & $\begin{array}{l}\text { Adjusted R } \\
\text { Square }\end{array}$ & $\begin{array}{c}\text { Std. Error of the } \\
\text { Estimate }\end{array}$ & Durbin-Watson \\
\hline 1 & $.628^{a}$ & .395 & .379 & 3.69055 & 1.506 \\
\hline
\end{tabular}

Skala Koefisien Korelasi Koefisien Korelasi ( r ) Hubungan adalah: (1) 0,00 - 0,199 Sangat Lemah, (2) 0,20 - 0,979 Lemah, (3) 0,40 - 0,599 Sedang, (4) 0,60 - 0,799 Kuat, (5) 0,80 - 1,0 Sangat Kuat. Nilai R atau korelasi yang terlihat dari tabel 6 adalah 0,628 artinya mempunyai hubungan yang kuat serta searah antara organizatonal commitment dan work life balance, maksudnya apabila work life balance naik maka organizational commitment juga naik. Nilai $\mathrm{R}$ Square atau koefisien determinasi $\left(\mathrm{R}^{2}\right)$ adalah 0,395 artinya variabel organizational commiment dapat terangkan oleh variabel work life balance $39,5 \%$, sisanya sebesar $60,5 \%$ dijelaskan oleh variabel lainnya.

\section{Uji Hipotesis}

Tabel 7: Uji Hipotesis

\begin{tabular}{|c|c|c|c|c|c|}
\hline \multicolumn{6}{|c|}{ ANOVA $^{a}$} \\
\hline Model & Sum of Squares & df & $\begin{array}{l}\text { Mean } \\
\text { Square }\end{array}$ & $\mathrm{F}$ & \\
\hline 1 Regression & 346.643 & 1 & 346.643 & 25.451 & $.000^{\mathrm{b}}$ \\
\hline Residual & 531.185 & 39 & 13.620 & & \\
\hline Total & 877.828 & 40 & & & \\
\hline
\end{tabular}

a. Dependent Variable: ORGANIZATIONAL COMMITMENT

b. Predictors: (Constant), WORK LIFE BALANCE

Dari tabel 5.5 dapat kita lihat F hitung sebesar 25.451, untuk itu dibandingkan dengan F tabel sbb:

a. Nilai F hitung pada uji F sebesar 25.451

b. Nilai degree of freedom df1 $=2-1=1$

c. $\mathrm{df} 2=\mathrm{n}-\mathrm{k}-\mathrm{l}=41-1-1=39$

d. Taraf signifikasi 0,5

e. Didapatkan nilai F tabel sebesar 4.09

f. Sehingga nilai Fhitung (25.451) > F tabel (4.09) sehingga dapat dikatakan bahwa Ho ditolak dan Ha diterima. Ini berarti Work Life Balance berpengaruh signifikan terhadap Organizational Commitment pada tingkat $(\alpha) 5 \%$. 


\section{PENUTUP}

Berdasarkan uraian dalam pembahasan diatas dapat disimpulkan Organizational Commitment dipengaruhi secara positif dan signifikan oleh Work Life Balance pada dosen di Sekolah Tinggi Ilmu Ekonomi Indragiri (STIE-I) Rengat. Untuk penelitian selanjutnya disarankan untuk melihat variabel selain work life balance yang mempengaruhi organizational commitment.

\section{REFERENCE}

Caught, K., \& Shadur. (2000). The Measurement Artifact In The Organizational Commitment Questionnaire. Psychological Reports , 87, 777-788.

Deery, M. (2008). Talent Management, Work-Life Balance And Retention Strategies. International Journal Of Contemporary Hospitality Management , 20 (7), 792-806.

Doherty, L., \& Manfredi, S. (2006). Action Research To Develop Work-Life Balance In A Uk University. Women In Management Review , 21 (3), 241-59.

Elliot, M. (2003). Work And Family Role Strain Among University Employees. Journal Of Family And Economic Issues, 24 (2), 157-180.

Fitrio, T., Apriansyah, R., Utami, S., \& Yaspita, H. (2019). The Effect of Job Satisfaction to Organizational Citizenship Behavior (OCB) Mediated by Organizational Commitment. International Journal of Scientific Research and Management, 7(09 SE-Economics and Management). https://doi.org/10.18535/ijsrm/v7i9.em01

Greenhaus, J., Collins, K., \& Shaw, J. (2003). The Relation Between Work-Family Balance And Quality Of Life. Journal Of Vocational Behavior, 63, 510-31.

Hudson. (2005). The Case for Work/Life Balance : Closing the Gap Between Policy and Practice. Hudson Highland Group, Inc

Kossek, E. E. (2005). Workplace Policies And Practices To Support Work And Families. In S. Bianchi, L. Casper, \& R. King (Eds.). Work, Family Health And WellBeing , 97-116.

Meyer, J., \& Allen, N. (1991). A ThreeComponent Conceptualization Of Organizational Commitment. Human Resources Management Review , 1 (1), 8189.

Mohd Noor, K., \& Amat, M. (2010). Keseimbangan Kerja Dan Kehidupan Dan Kepuasan Kerja Ahli Akademik Di Institusi Pengajian Tinggi Malaysia. Paper Presented To Leadership And Management Seminar, Nilai, Negeri Sembilan.

Moore, F. (2007). Work-Life Balance: Contrasting Managers And Workers In An Mnc. Employee Relations , 29 (4), 385-99.

Mowday, R. P. (1982). Employee- Organization Linkage: The Psychology of Commitment, Absenteeism, And Turnover. New York: Academic Press .

Ning, T. (2004). Antecedents And Consequences Of Role Stress In Hospitality Industry. National University Of Singapore, Department Of Management And Organization , Singapore.

Noor, K. M. (2011). Work-Life Balance And Intention To Leave Among Academics In Malaysian Public Higher Education Institutions. International Journal Of Business And Social Science, 1-9.

R. Burke Johnson, L. C. (2010). Educational Research:Quantitative, Qualitative And Mixed Approaches (5th Ed.). Sage.

Sekaran, Uma. (2011). Research Methods for business Edisi I and 2. Jakarta: Salemba Empat Sugiyono. (2017). Metode Penelitian Kuantitatif, Kualitatif, dan R\&D. Bandung : Alfabeta, $\mathrm{CV}$

Veenhoven, R. 1988. The utility of happiness. Social indicators research, 20(4), 333354 